\title{
The Didactical Design of Properties of Triangles based on Pecle Traditional Games in Primary School
}

\author{
Epon Nur'aeni ${ }^{1}$, Fitri Rohmayati ${ }^{2}$, Muhammad Rijal Wahid Muharram ${ }^{3}$, Oyon Haki \\ Pranata $^{4}$, Hodidjah $^{5}$, Ika Fitri Apriani ${ }^{6}$ \\ \{nuraeni@upi.edu ${ }^{1}$, fitrirohmayati@gmail.com ${ }^{2}$, rijalmuharram@upi.edu ${ }^{3}$ \}
}

Universitas Pendidikan Indonesia Kampus Tasikmalaya, Jl. Dadaha No. 18 Tasikmalaya City ${ }^{1,2,3}$

\begin{abstract}
The research is based on the emergence of learning obstacles of students on the topic of properties of triangles. The didactical design that the researcher designed is one of the first steps to overcome learning obstacles. The aim of the research was to develop a didactical design of the properties of triangles based on péclé traditional games for thirdgrade students of primary school. The research was conducted in the City of Tasikmalaya, Indonesia. The study used descriptive qualitative methods. The research instrument is equipped with teaching materials in the form of Student Activity Sheets (SAS). Data collection used is interviews, tests, attitude scale questionnaires and documentation. The results of the study indicate that the design that the researcher can use by teachers and elementary students to enrich the learning design, and can be developed further to minimize the obstacle learning of students in mathematics.
\end{abstract}

Keywords: the properties of triangles, learning obstacles, péclé traditional games

\section{Introduction}

This research is motivated by the results of a preliminary study of the learning obstacles faced by students in learning geometry, specifically regarding the material properties of triangles in grade III elementary school. Learning geometry is important for students to master in order to foster children's logical thinking skills, fostering children's thought processes and learning geometry can provide not just one example [1]. Geometry also is one of the mathematic branches existing from several years old ago [2].

Researchers find learning obstacles faced by students. There are three types of learning obstacles that appear in preliminary studies, as follows: Figure 1 shows some students mistakenly distinguished the names of triangles. Students have difficulty differentiating isosceles triangles and equilateral triangles. In addition, students mistakenly determine the names of the right triangle and random triangles. Figure 2 shows students do not yet know the properties of triangles. In addition, students have not been able to describe the types of triangles precisely.

Figure 3 shows students have not been able to give examples of objects that are shaped in the shape of triangles in everyday life. Based on the learning obstacles found, the researcher made a mathematics learning design especially on the properties of triangles based on the Péclé traditional games. Traditional games will play an important role in learning mathematics [3]. In addition, traditional games encourage students to be more creative and work together to become winners [3]. 


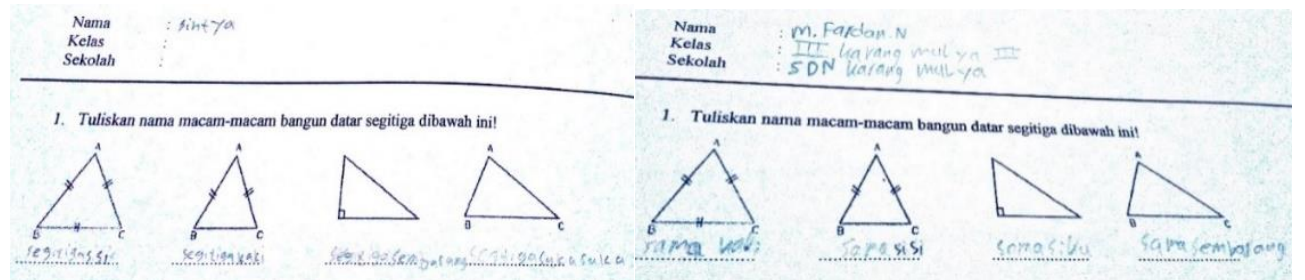

Fig. 1. Learning Obstacles type 1

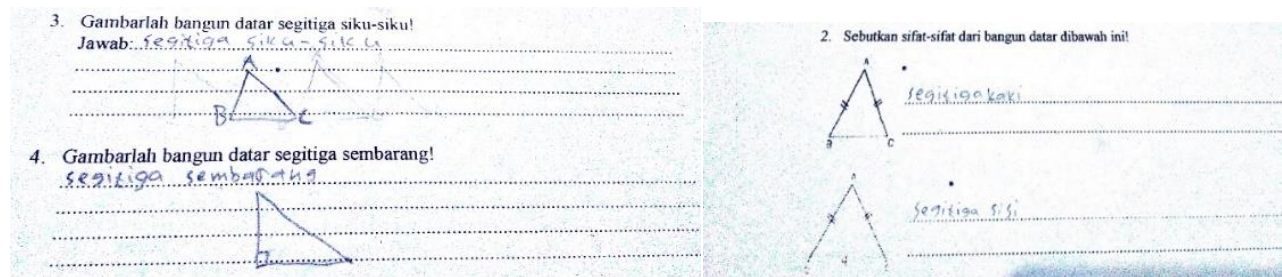

Fig. 2. Learning obstacles type 2
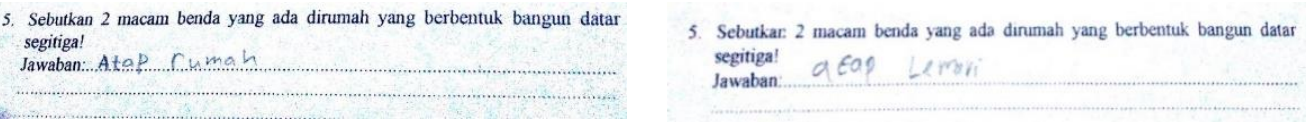

Fig. 3. Learning obstacles type 3

\section{Methods}

Researchers used a descriptive qualitative method of the Didactical Design Research (DDR) model. There are three stages of the DDR model, namely: Prospective analysis, metapedadidactical analysis, and retrospective analysis [4]. The study was conducted in the city of Tasikmalaya. There are two primary schools which are used as research locations.

Data were collected using triangulation techniques. The triangulation technique is done through observation, interviews, and documentation. In addition, data were collected using tests for students.

\section{Result and Discussions}

Didactical design is arranged based on three stages, namely: Prospective analysis, metapedadidactical analysis, and retrospective analysis. The following explanation at each stage.

\subsection{Prospective Analysis}


The researcher determines the core competencies (KI) and Basic Competencies (KD) used in the study. The KD used is shown in the following Table $\mathbf{1 .}$

Table 1. Basic Competencies

\section{Basic Competencies (KD)}

1.12 Analyze various plane based on their properties

4.12 Classifying a variety of shapes based on the properties they have.

Researchers compile indicators and learning objectives. After that, researchers compiled pedagogical didactical anticipation (ADP) to minimize learning obstacles. Indicators and learning objectives are shown in the following Table 2.

Table 2. Indicators and learning objectives

\begin{tabular}{|c|c|}
\hline Learning Indicator & Learning objectives \\
\hline $\begin{array}{l}\text { 1.12.1 Comparing types of } \\
\text { triangles based on their properties. } \\
\text { 4.12.1 Shows the types of triangles } \\
\text { and their properties } \\
\text { 4.12.2 Draw a picture of types of } \\
\text { triangles }\end{array}$ & $\begin{array}{l}\text { 1. By observing the picture shown by the teacher, } \\
\text { students can compare the types of triangles } \\
\text { precisely. } \\
\text { 2. Through simulation of péclé traditional games, } \\
\text { students can compare the types of triangles based on } \\
\text { their exact nature. } \\
\text { 3. Through discussion, students can show the types of } \\
\text { triangles and their properties correctly. } \\
\text { 4. Through observing the péclé traditional games, } \\
\text { students can draw pictures of the types of triangles } \\
\text { precisely. }\end{array}$ \\
\hline
\end{tabular}

In the prospective analysis phase in the preliminary design, the researcher compiled a lesson plan and student activity sheets (SAS) consisting of 2 activities along with an ADP. In SAS activity 1 , students are instructed to do simulations with the péclé traditional games.

Figure 4 shows the SAS that students used in activity 1. After completing the simulation, students were instructed to work on activity 2 .

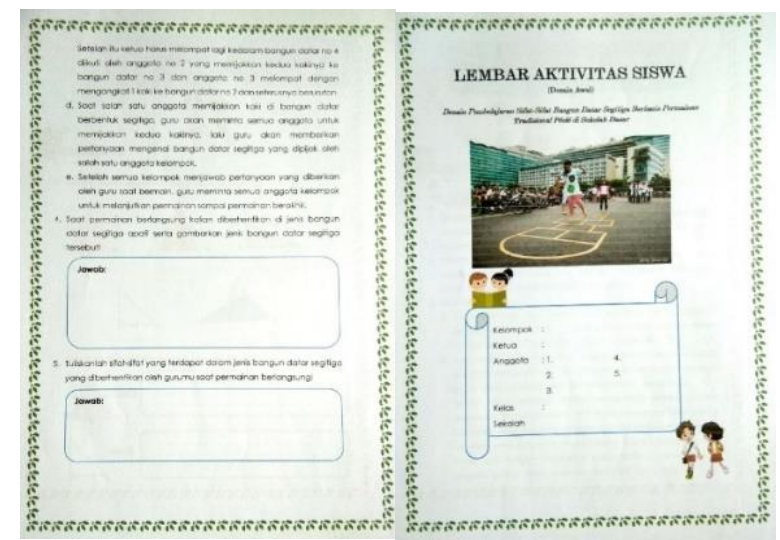

Fig. 4. Layout of the Student Activity Sheet Activity 1

Figure 5 shows SAS activity 2 which prioritizes the ability of students' understanding during the learning process of the properties of triangles figure through the péclé traditional 
games. The researcher compiles predictions of student responses in learning as well as ADP as shown in Table 3 below.

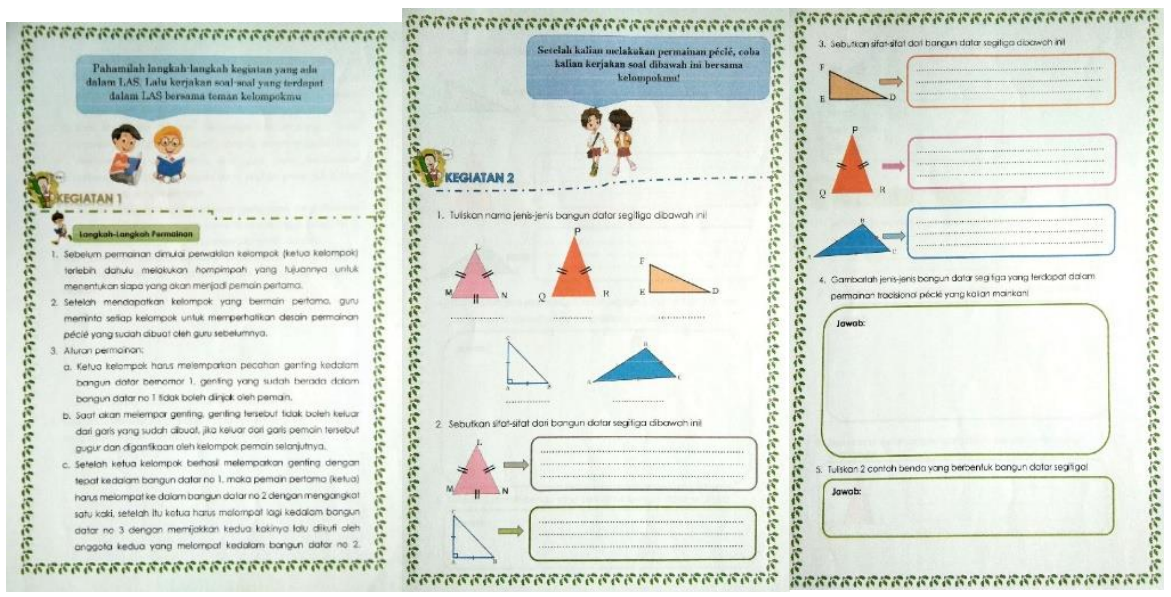

Fig. 5. Layout Student Activity Sheet Activity 2

Table 3. Predictions of student responses and ADP

No. $\begin{aligned} & \text { predictions of student responses } \\ & \text { Activity } 1\end{aligned}$
$\begin{aligned} & \text { Students have difficulty understanding the steps of péclé } \\ & \text { traditional games. }\end{aligned}$
Students have difficulty in determining the name of the
type of triangles figure that is stepped on by a member
when the game is stopped by the teacher.

\section{Activity 2}

Students erroneously determine the names of the types of triangles.

Students have difficulty in determining the properties of 2 triangles.
Give students an explanation of the steps in the péclé traditional games.

The teacher shows the types of triangles made of origami paper and gives instructions to students about the types of triangles they stand on.

- All groups observe the triangles which are stepped on by one of its members.

- The teacher gives a clue about the triangles which one member steps on.

- The teacher shows again the types of triangles made of origami paper.

- The teacher instructs students to take media types of triangles and ask students to observe their properties.

- Students to revisit the arena of péclé to find out the properties of triangles. 
Students err in describing the types of triangles found in the péclé arena. the form of triangles.
- Students review the arena of péclé traditional games made by the teacher in front of the class.

- The teacher gives a clue about the objects that are often used by students in the form of triangles.

\subsection{Implementation of Preliminary Didactical Design}

After conducting a preliminary didactical design prospective analysis with a hypothetical learning trajectory and pedagogical didactical analysis, the researcher implemented the preliminary design in one of the primary schools in Tasikmalaya City. In the process of implementation, the teacher used SPADE (singing, playing, analyzing, discussing, evaluating). SPADE is an innovative learning model [5].

The initial learning activity begins with an activity showing several types of triangles made of origami paper. Next, the teacher gives questions to students about the differences between each type of triangles formed on the origami paper. Students begin to observe and identify the properties of the triangles formed.

Furthermore, confirmation is done by the teacher through péclé traditional games. Students are divided into 7 groups and asked to observe the péclé design created by the teacher. Before the game starts, the group leader makes a compilation to get the order of starting the game as shown in Figure 6 below.

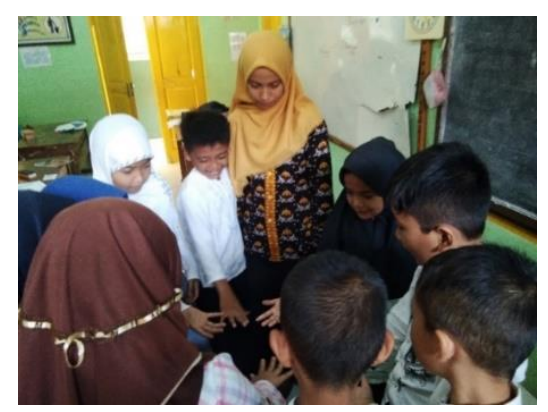

Fig. 6. Hompimpah Activities to Determine the First Player

Students who win a lot are appointed to do the péclé traditional games simulation. In addition, the whole group was asked to determine the order of jumps in the arena.

Figure 7 shows the péclé traditional games activities carried out by students in groups. Students stop to jump when there are several group members who step on a triangle. Next, all group members who play are given questions by the teacher about the type of plane and its properties. Figure 8 shows the question and answer process carried out by the teacher to students. When the teacher gives a question the students' responses arise which have difficulty in answering the names of Triangles and their properties. The teacher gives a pedagogical didactical anticipation (ADP) in the form of asking one of the students to observe from a distance the flat build which is stepped on by one of its members. The teacher also provides instructions on the plane that the group members stand on to help students answer questions. If all group members can answer the questions asked by the teacher, then the game continues. 
After finishing playing the teacher will ask the group that has been playing to work on activities 1 numbers 4 and 5 in the discussion.

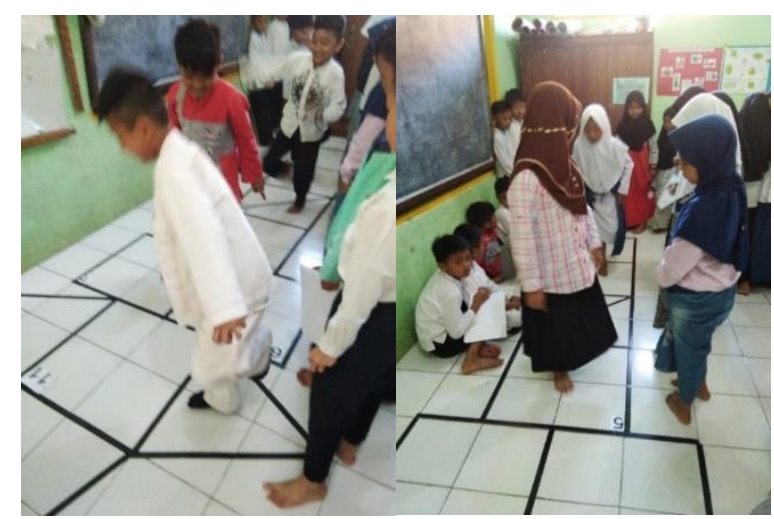

Fig. 7. Péclé Traditional Games Activity

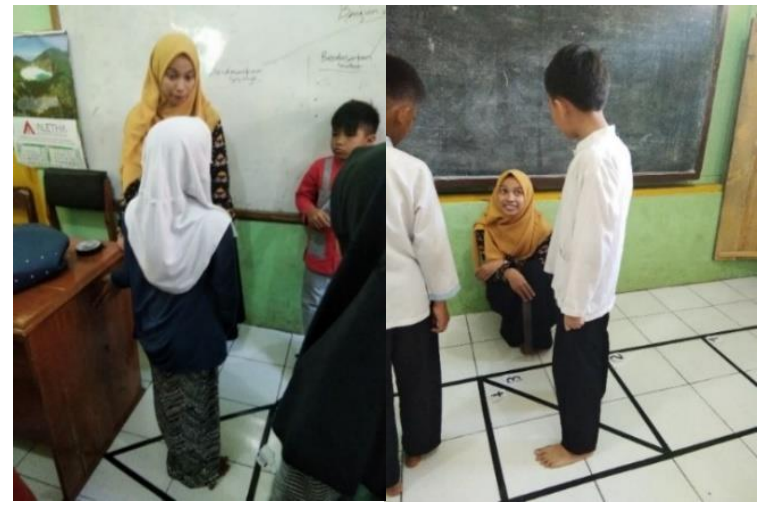

Fig. 8. Question and Answer Activities Regarding the Characteristics of a Triangles

The teacher instructs students to continue activity 2 . In the activity 2 the students' responses appear to be difficult in determining the properties of triangles and draw one of triangles requested in LAS activity 2 as shown on Figure 9 and Figure 10, to deal with the student's difficulties, the researcher undertakes pedagogical didactic anticipation (ADP) by asking all group members to see the péclé arena, then the teacher also gives a clue about the properties possessed by triangles.

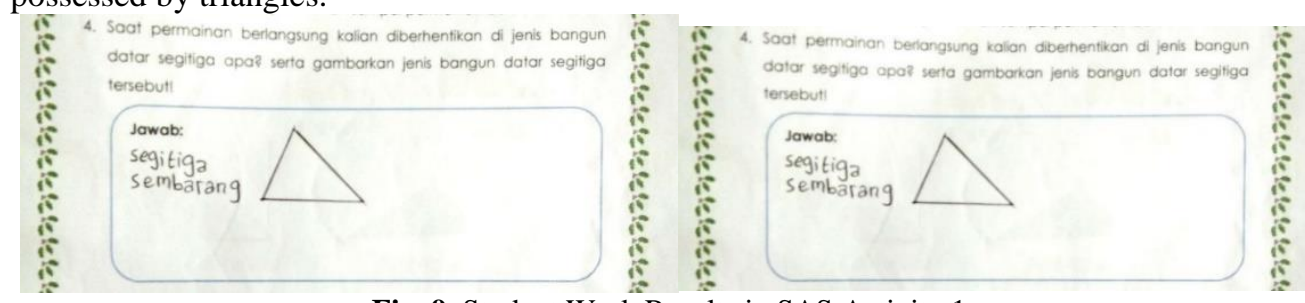

Fig. 9. Student Work Results in SAS Activity 1 


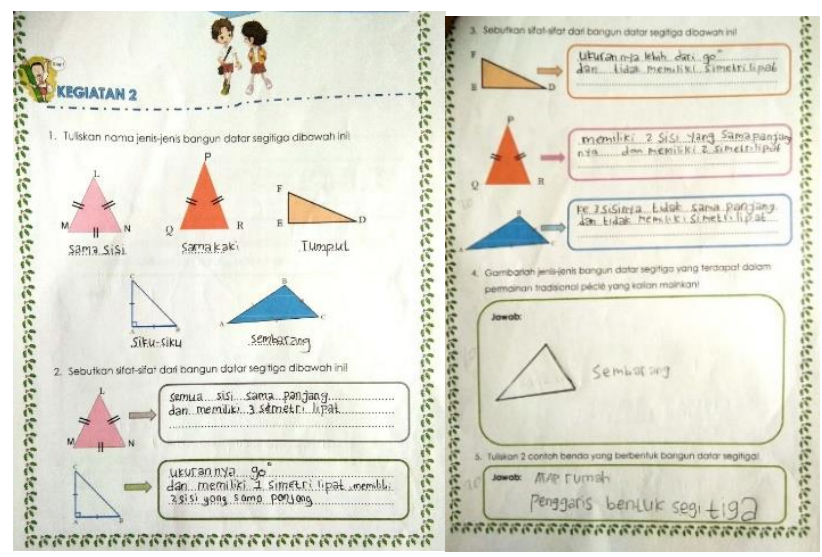

Fig. 10. Student Work Results in SAS Activity 2

\subsection{Retrospective Analysis of Preliminary Design}

Based on the results of the analysis of the preliminary design implementation, there are several things that need to be improved, both in the form of a lesson plan, student activity sheet and prediction of student responses. Improvements made by this researcher are based on input from supervisors, student responses and expert judgment analysis. The revised improvements are:

Revision of Lesson Plan. Based on the results of discussions with the supervisor, the allocation of time needed in the design of the lesson plan needs to be increased to $4 \times 35$ minutes. In the steps, the core activities begin by asking students questions about some types of triangles made by the teacher through origami paper.

Revision of Student Activity Sheet. Where in the SAS in the preliminary design of activity 1 question number 4 students had difficulty in answering, based on the results of discussions with the supervisor, in activity 1 question number 4 was given a table to facilitate students in answering. In addition, in the activity 2, students experienced difficulties in questions no. 2 and 3 , wherein the preliminary design the researcher did not mention the instructions regarding the name of the triangles on the side, so students were wrong in answering it.

Revision of Prediction of Student Responses. Researchers analyze students' responses during the preliminary design implementation and produce several things that need to be improved. The results of the analysis in the form of students' difficulties in remembering the properties of triangles that students already understand in playing péclé traditional games.

\subsection{Prospective Analysis Revised Design}

Basically, at the prospective analysis stage, this revised design is the same as the preliminary design, however, there are additions to the time allocation and several steps of activities to facilitate the delivery of material to students. In addition, there are changes to the SAS and ADP. 


\subsection{Implementation of Revised Designs}

The revised design was implemented in primary school. The steps of learning are not much different. However, there are additions and adjustments to the evaluation results from the preliminary design implementation. The teacher starts the lesson by showing the types of triangles made from origami paper. In addition, the teacher encourages students to express the properties possessed by triangles figure. Next, the teacher encourages students to form groups.

Figure 11 shows students doing a lot to get a turn in the péclé traditional games. Before the game starts, the jump order is determined in advance by the whole group. Furthermore, the learning process is the same as in the previous design implementation.

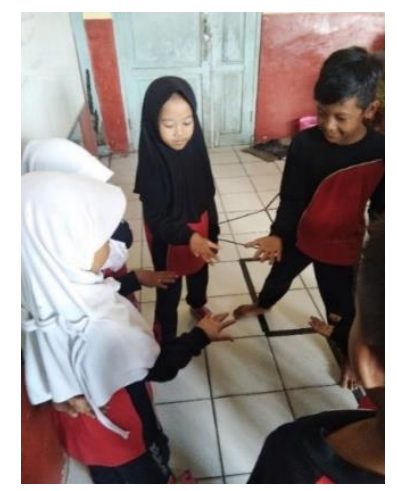

Fig. 11. Hompimpah Activities to Determine the First Player

\subsection{Retrospective Analysis of Design Revisions}

Student responses that arise during the learning process can be predicted making it easier to provide ADP to students. In addition, barriers to learning that have arisen previously can be minimized when implementing revised designs.

\subsection{Discussions}

However, the researcher makes a hypothetical learning trajectory when preparing a didactical design. The HLT includes indicators of learning, learning objectives, steps of learning activities, student learning hypotheses and ADP whose aim is to minimize the learning obstacles that arise.

Didactical designs are arranged based on the characteristics of primary school students who are at a concrete operational stage where students still think rationally and have not been able to deal with abstract material [6]. In addition, learning is made by developing games to be more easily understood by students [7]. This implies that the objects contained in the péclé traditional games are concrete objects that can be seen directly by students [8]. Learning is designed for one meeting where the time needed is $3 \times 35$ minutes. At this meeting, the aim is for students to understand the properties of triangles found in the péclé arena.

Didactical design that has been prepared is implemented into the learning process in class III. Researchers found an occurrence that matched the prediction of student responses. However, 
researchers also found students' responses that had not been predicted. However, this does not become an obstacle during the design implementation process.

In implementing the revised design of student responses that appear in accordance with the predictions that have been designed. Based on the results of the analysis on the implementation of the preliminary design, researchers anticipate by simplifying questions on each activity contained in the SAS. In addition, students' responses which were still wrong in mentioning the properties of triangles were anticipated by asking students to measure the length of triangles.

Students show enthusiastic responses to the learning design of the properties triangles. In addition, students are also active when participating in learning. Students find it easier to understand the material by using péclé traditional games as evidenced by improved test results.

\section{Conclusion}

Didactic design of the properties of triangles based on the traditional game Péclé based on learning obstacle with the following types are:

a. Learning Obstacle type 1: Determine the types of triangles names.

b. Learning obstacle type 2: understand the concepts of triangles.

c. Learning obstacle type 3: the Connecting concept of triangles in everyday life.

The implementation of the didactic design of the properties of triangles based on the péclé traditional games was implemented in primary schools. After completing the preliminary design implementation process, it is continued with a retrospective analysis of the initial didactical design and produced several improvements to the lesson plan, student activity sheets (SAS), evaluation and Pedagogical Didactical Anticipation (ADP). Based on improvements to the preliminary design, a revised didactical design was arranged with regard to the retrospective analysis that researchers made in the preliminary design. Through péclé traditional games, students become easier to understand the properties of triangles.

The students' responses to the didactical design of triangles based péclé traditional games were very enthusiastic during the learning process. Students are also enthusiastic about accepting the material properties of triangles, and students are also very enthusiastic in mentioning the properties of triangles presented in péclé traditional games.

\section{References}

[1] Clements, Douglas H.: "Geometric and spatial thinking in early childhood education." Engaging young children in mathematics: Standards for early childhood mathematics education. pp. 267-297 (2004).

[2] Hartshorne, R.: Geometry: Euclid and beyond. Springer Science \& Business Media. (2013)

[3] Prahmana, R. C. I., Zulkardi, Z., \& Hartono, Y.: Learning multiplication using indonesian traditional game in third grade. Journal on Mathematics Education, 3(2). pp.115-132 (2012).

[4] Fuadiah, N. F., \& Suryadi, D.:Teaching and Learning Activities in Classroom and Their Impact on Student Misunderstanding: A Case Study on Negative Integers. International Journal of Instruction, 12(1). pp.407-424 (2012).

[5] Nur'aeni, E. et.al.: Pengembangan Model Pembelajaran Geometri Berbasis Permainan Tradisional Kampung Naga untuk Siswa Sekolah Dasar. UPI, Indonesia (2018) 
[6] Brezovszky, B., McMullen, J., Veermans, K., Hannula-Sormunen, M. M., Rodríguez-Aflecht, G., Pongsakdi, N., ... \& Lehtinen, E.:Effects of a mathematics game-based learning environment on primary school students' adaptive number knowledge. Computers \& Education, 128. pp. 63-74(2019). [7] Nuraini, N. L. S., \& Isbadria, N.: Implementation of Game-Based Learning in Elementary School: A Content-Analysis Study. In International Conference on Education and Technology (ICET 2018). Atlantis Press.(2018)

[8] Nur'aeni, L. E., Pranata, O. H., Hodidjah, H., Apriani, I. F., \& Suryati, C.:Didactic design of circumference and area of square based on Indonesia traditional game in elementary school. In Journal of Physics: Conference Series (Vol. 1318, No. 1, p. 012020). IOP Publishing (2019). 